\title{
Heat Sealing Evaluation and Runnability Issues of Flexible Paper Materials in a Vertical Form Fill Seal Packaging Machine
}

\author{
Mahdi Merabtene, ${ }^{*}$ Panu Tanninen, Juha Varis, and Ville Leminen \\ Vertical form fill seal machines are commonly used to form pouches. This \\ paper aimed to optimize the sealing parameters and evaluate the \\ runnability of flexible paper-based packaging materials with a polyethylene \\ coating, differentiated by their grammages and thicknesses. This was \\ done in comparison with a commercial plastic film, an oriented \\ polypropylene and polyethylene laminate, using two different sealing jaw \\ patterns in an industrial-scale vertical form fill seal machine. Based on the \\ results obtained, the first observable seal was found at a sealing \\ temperature of $90{ }^{\circ} \mathrm{C}$ for the paper-based material and a sealing \\ temperature of $100{ }^{\circ} \mathrm{C}$ for thermoplastic film, both at a dwell time of $2 \mathrm{~s}$. It \\ was shown that the paper-based material had a larger sealing window, up \\ to a sealing temperature of $220^{\circ} \mathrm{C}$, before the material started to turn \\ brown, while the thermoplastic film shrank at a sealing temperature of 140 \\ ${ }^{\circ} \mathrm{C}$. Several peel and compression strength tests were performed to \\ evaluate the flexible paper-based material. Furthermore, several hindering \\ issues were observed in the paper-based material during the production \\ runs. These included wrinkling, web buckling, friction in the forming tubes, \\ pouches airtightness, etc. As such, recommendations for further \\ investigations and future studies are given.
}

DOI: 10.15376/biores.17.1.223-242

Keywords: Heat sealing; Paper-based packages; Seal strength; Compression strength; VFFS machine

Contact information: Department of Mechanical Engineering, Lappeenranta-Lahti University of

Technology LUT, Yliopistonkatu 34, Lappeenranta 53850 Finland;

*Corresponding author: mahdi.merabtene@lut.fi

\section{INTRODUCTION}

Food packaging provides a means to maintain food safety, marketing, ease of transportation, etc. The packaging is extremely important in terms of protecting the packaged content from crushing or external environmental aspects, e.g., atmospheric moisture (Hishinuma 2009). A primary objective for EU legislation concerning packaging and packaging waste is to reduce the overall volume of packaging waste. One solution is to use strong, thinner, lighter-weight materials and encourage recyclable packaging materials, e.g., paperboard, flexible paper, bio-monomer, and biodegradable alternative (Mullineux et al. 2007; Ilhan et al. 2021). For the past few years, flexible packaging materials have received considerable interest and have experienced strong growth for fast moving consumer goods (FMCG). In 2019, the total sales of flexible packaging reached $\$ 228$ billion with an annual growth of 3.3\%, and this figure is estimated to reach $\$ 269$ billion by 2024 (Pira 2021). 
Flexible packaging applications include frozen food, pharmaceutical products, and cosmetic applications. The shelf-life of the product depends on the sealing integrity and the barrier properties of the flexible material. Several industrial machines are used for the closure of flexible materials by applying heat and pressure towards the inner layer of the film (Aithani et al. 2006). Typically, the inner layer consists of sealant layers that become partially molten, and wetting is achieved. The molecular segments are freely diffused across each other to create an entanglement, such that a strong bond is then achieved upon cooling (Morris 2002). Quite frequently, product deterioration is caused due to seal failure (Aithani et al. 2006).

Packaging manufacturers continue to improve the performance of packaging machines to suit runnability and to meet the needs of flexible packaging materials and the customers. Vertical form fill seal (VFFS) machines are used to produce pillow and block bottom bags from a reel of packaging material for numerous items, e.g., crisps, cereals, biscuits, fertilizers, and a wide range of other applications (Morris 2017). A VFFS machine consists of the following key elements: a film handling unit, a forming shoulder and tube, a longitudinal and vertical/horizontal sealer, and a filling dozer. A schematic diagram of a VFFS is shown in Fig. 1. The transport belt pulls the film from the reel through a series of rollers to create a web film. The web film is then guided and flows over the forming shoulder and towards the forming tube. As the outer edges of the film meet in the forming tube, the vertical sealing bar creates a vertical seam and the horizontal sealing jaws create the top and bottom seams, which are cut by a knife as the product falls from the dozer. The filled quantity of the pouch is programmed by weight and timing to create a dynamic nonstop flow of production (Dudbridge 2016).

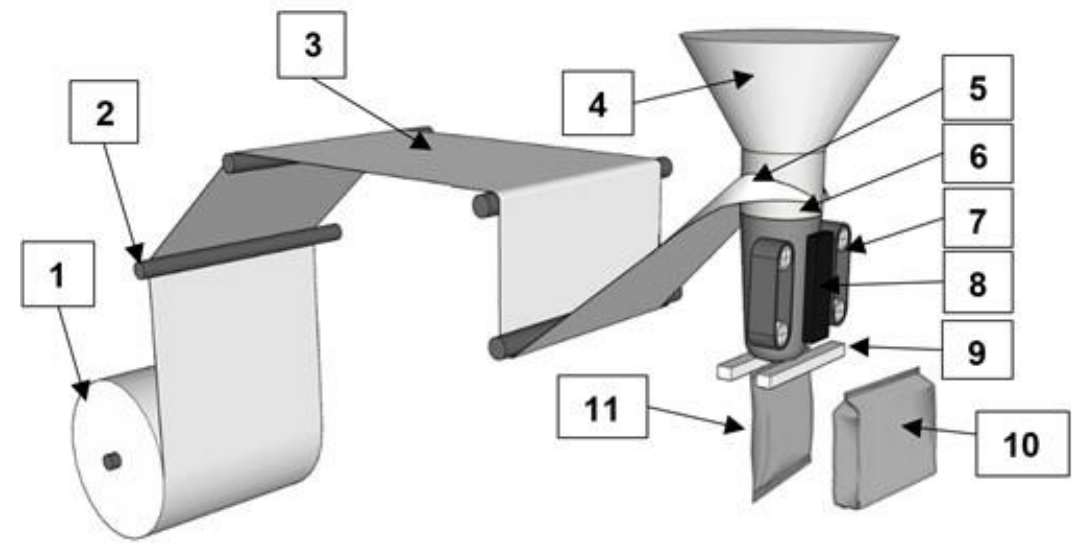
1. Reel
2. Rollers
3. Film Web
4. Dozer
5. Forming shoulder
6. Forming tube
7. Transport belt
8. Vertical seal bar
9. Horizontal seal jaw
10. Block bottom bag
11. Pillow bag

Fig. 1. Schematic diagram of a VFFS machine

To date, the majority of flexible packaging films used on VFFS machines are based on thermoplastic polymers such as simple polyethylene films for products ranging from potatoes to complex multilayer polymer films, e.g., low density polyethylene (LDPE), linear low density polyethylene (LLDPE), polypropylene (PP), oriented polypropylene (OPP), cast polypropylene (CPP), metallized cast polypropylene (MCPP), polyethylene terephthalate (PET), metallocene plastomers (MP), etc., for high end applications (Dudbridge 2016). Due to their unique material characteristics, these multilayer laminated films perform well on high-speed packaging machines. However, when it comes to sealing, each material behaves differently and requires different sealing conditions. 
In packaging, the optimal and correct design parameters are necessary to achieve a high-quality seal. The effect of the heat-sealing performance using laboratory sealers and VFFS machines for flexible packaging materials has been previously studied. Theller (1989) studied the heat sealability of flexible web materials, low density polyethylene (LDPE) coextruded films, and high-density polyethylene/ethylene vinyl acetatepolybutylene (HDPE/EVA-PB) coextruded films using a precision laboratory sealer with a serrated tool configuration. It was reported that the sealing temperature and the dwell time had a major influence on the seal strength, whereas the sealing pressure had very little effect on the seal strength (Theller 1989). Meka and Stehling (1994) drew similar conclusions to Theller (1989) using several polyethylene films, e.g., HDPE, LDPE, EVA, etc., where the effect of the heat-sealing variables on the sealing properties were primarily controlled by the sealing temperatures and dwell time, rather than the sealing pressure. Mueller et al. (1998) studied the effect of the heat-sealing variables on the seal strength using a flexible linear low-density polyethylene (LLDPE) film. The seal temperature used ranged from 100 to $130{ }^{\circ} \mathrm{C}$ with a dwell time of 1 to $100000 \mathrm{~s}$, to characterize the development of interfacial strength. Mueller et al. (1998) reported that the materials achieved a good seal at higher temperatures, i.e., greater than $115^{\circ} \mathrm{C}$.

Other extensively studied thermoplastic polymers include OPP. Tetsuya et al. (2005) used sealing temperatures ranging from 100 to $250{ }^{\circ} \mathrm{C}$ to investigate the effect of the heat-sealing temperature on the mechanical properties and morphology of OPP/CPP laminate films. They reported that the peel strength sharply increased from zero at a sealing temperature of $110^{\circ} \mathrm{C}$ to its maximum value at a sealing temperature $120{ }^{\circ} \mathrm{C}$, after which a progressive decrease was observed. However, the tensile strength increased until the sealing temperature was $120{ }^{\circ} \mathrm{C}$ but then gradually decreased until it reached $170{ }^{\circ} \mathrm{C}$. Tetsuya et al. (2005) concluded that the tensile strength was influenced by the orientation of the laminate. Furthermore, Hashimoto et al. (2005) investigated the dynamic characteristics and macromolecular structure within the heat-sealed portion of OPP/CPP heat seals made using an impulse type heat-sealing machine. They concluded that the notched strength was stronger in the transverse direction compared to the machine direction. Additionally, at sealing temperatures greater than $150{ }^{\circ} \mathrm{C}$, the orientation of the OPP film was found to be relaxed (Hashimoto et al. 2005). Yuan and Hassan (2007) studied the effect of the bar sealing parameters on the heat seal strength of OPP/MCPP laminate film. Based on these results, Yuan and Hassan (2007) were able to develop a bar sealing process window, and they characterized the modes of failures according to ASTM standard F88 (2015).

Several authors have studied the sealing of sustainable materials, e.g., paperboard trays. The effect of the heat-sealing temperature on the required dwell time has a clear effect on the gas tight sealing process. However, these parameter optimizations vary with different material combinations (Leminen et al. 2012). To analyze the leakage of the heatsealed creases, various methods, e.g., the casting of the samples in an acrylic resin and light microscope imaging, were found to be the most suitable method (Leminen et al. 2015d). Leminen et al. (2015a) studied the air tightness of press-formed polymer-coated paperboard trays and the heat-sealing process of lidding films into the trays. Their investigation demonstrated a satisfactory modified atmosphere packaging (MAP) tightness and liquid tightness. Leminen et al. (2015b) further investigated the influence of the sealing pressure at different sealing temperatures to evaluate the effect of the seal tightness of press-formed polymer-coated paperboard trays. It was shown that the sealing pressure was an essential parameter concerning the tightness of the heat seal in paperboard trays. 
Furthermore, Leminen et al. (2017) demonstrated that increasing the sealing pressure had a positive effect on heat sealing and maintained a reduced oxygen content inside the sealed trays if the quality of the seal was satisfactory.

The sealing behavior of paper-based flexible packaging materials was studied by Hauptmann et al. (2020), who evaluated the effect of the sealing conditions on the hot- and cold-tack behavior of thermoplastic and paper-based laminate film under different sealing parameter conditions on a laboratory scale. Several sealing parameters were considered, and Hauptmann et al. (2020) concluded that the seal strength of the paper material highly depends on their moisture content and the storage climate control before they are applied to the packaging machines. Furthermore, Hauptmann et al. (2021) investigated the air tightness using a rhodamine test to evaluate the sealing behavior of the same materials used in their previous studies. It was concluded that thermoplastic materials can produce gastight packages, whereas the paper-based materials were not gastight within the selected operational sealing parameters (Hauptmann et al. 2021).

The majority of the previous studies focused only on laboratory-scale experiments using laboratory sealers with polyolefins materials. The primary objective of this scientific study is to evaluate the sealing parameters and evaluate the runnability of paper-based flexible packaging material as well as to determine the hindering issues using an industrialscale VFFS machine.

Two different jaw patterns, i.e., a serrated and flat sealing tool, were used to investigate the influence of the peel and compression strength of the pouches. More importantly, the effects of the material and the coating thickness at a fixed sealing pressure and different combinations of sealing temperatures and dwell times were analyzed. The results of the sealants were compared and verified using the modes of failure outlined in ASTM standard F88 (2015).

\section{EXPERIMENTAL}

\section{Materials}

Three sample materials were used in this study, two polymer-coated paper-based materials and one thermoplastic material. The thermoplastic material was used as a reference. All three materials are commercial laminated films used for VFFS machines. The paper-based materials were provided by Stora Enso (Imatra, Finland) (Stora Enso 2021), which is commercially branded as LumiFlex Light PE. The paper-based material is based on wood-free flexible packaging paper, which consists of three layers. The inner layer is PE coated from the inside of the film roll.

On a reverse side of the material, a pigment coating is added on the top side to create a printable surface. The two LumiFlex paper-based materials (Paper 70 + 15 PE and Paper $90+30 \mathrm{PE}$ ) differed in their grammages and thicknesses. The thermoplastic film (Plastic Ref) was manufactured by Tecnopack Univel S.r.l. (Pavia, Italy). It is comprised of oriented polypropylene (OPP) with a sealant layer of polyethylene (PE) laminate. The technical specifications and characteristics of the materials used are summarized in Table 1 .

The moisture content of the paper-based materials was determined in this study. The moisture content was measured using a PMB 53 moisture analyzer (ADAM Equipment, Oxford, CT), which has a readability and repeatability of $0.001 \mathrm{~g}$. The paper- 
based materials were stored in a controlled climate chamber to ensure a fixed temperature of $23{ }^{\circ} \mathrm{C}$ with a relative humidity $(\mathrm{RH})$ of $50 \%$.

Table 1. Technical Specifications for the Thermoplastic Reference and LumiFlex Material

\begin{tabular}{|c|c|c|c|}
\hline & Plastic Ref. & Paper 70 + 15 PE & Paper $90+30$ PE \\
\hline Polymer Coated Paper & No & Yes & Yes \\
\hline Basepaper $\left(\mathrm{g} / \mathrm{m}^{2}\right)$ & NA & $70 \pm 4 \%$ & $90 \pm 4 \%$ \\
\hline PE coating $\left(\mathrm{g} / \mathrm{m}^{2}\right)$ & $35 \pm 6 \%$ & $15 \pm 5 \%$ & $30 \pm 5 \%$ \\
\hline Grammage $\left(\mathrm{g} / \mathrm{m}^{2}\right)$ & $49.65 \pm 6$ & $85 \pm 4 \%$ & $120 \pm 4 \%$ \\
\hline Thickness $(\mu \mathrm{m})$ & $52 \pm 6 \%$ & $78 \pm 5 \%$ & $124 \pm 5 \%$ \\
\hline Moisture $(\% \mathrm{M})$ & NA & $6.13 \pm 10 \%$ & $8.91 \pm 10 \%$ \\
\hline
\end{tabular}

\section{Methods}

The heat-sealing parameters were determined using an RDM HSB-1 laboratory heat sealer (RDM Testing Equipment, Hertfordshire, United Kingdom) with a flat sealing tool profile. The device clamped two pieces of materials between the flat sealing tools, which have a width of $25 \mathrm{~mm}$. The objective of this task is to primarily investigate the necessary heat-sealing temperatures and dwell times, as well as the effect of various sealing pressures, required to seal the materials. The operating window was then determined for performing practical experiments with the industrial-scale machine, VFFS GKS-Compack CP350 Plus (GKS Packaging b.v., Eindhoven, Netherlands), as shown in Fig. 2.

Two sealing tool profiles with a width of $11 \mathrm{~mm}$ were used (a flat and serrated tool), as they are commonly used for commercial food packaging applications. The surface pressure of the sealing jaws of the serrated and flat tool were 3.8 and 3.1 bar, respectively. The forming tube and shoulder came with a diameter of $87 \mathrm{~mm}$ and a width of $140 \mathrm{~mm}$, respectively. This was to produce pillow bags with a width of $140 \mathrm{~mm}$, with the length customizable by the GKS VFFS machine to $200 \mathrm{~mm}$. Both bars operated at the same temperature and were kept closed between sealing to minimize heat loss and temperature fluctuations. The sealing tool surface temperature was reported with a repeatability of \pm $0.2{ }^{\circ} \mathrm{C}$.

For this study, the sealing criteria were chosen to be from 100 to $140{ }^{\circ} \mathrm{C}$ in $10{ }^{\circ} \mathrm{C}$ increments and dwell times between 0.5 and $2 \mathrm{~s}$ in $0.5 \mathrm{~s}$ increments. The sealing pressure was kept constant at 5 bar, as previous scientific studies have stated that an increase in pressure does not considerably enhance the seal strength (Mullineux et al. 2007). To confirm this statement, the effect of the sealing pressure on the paper-based material were tested using RDM laboratory heat sealer with the dwell time fixed at $2 \mathrm{sec}$ and the sealing temperatures ranging from 80 to $100{ }^{\circ} \mathrm{C}$ in $10{ }^{\circ} \mathrm{C}$ increments. The calculated surface pressure of the different surface geometries of the sealing tool profiles are shown in Table 2. The forces presented are based on the data sheets provided by the manufacturer.

The seal strengths of the pouches were examined with a Shimadzu AGS-1kN (Shimadzu, Kyoto, Japan) universal testing machine with a $1 \mathrm{kN}$ load cell with an accuracy of $\pm 1 \%$ (Fig. 3a). The heat seal samples were prepared according to ASTM standard F88 (2015) guidelines using a $180^{\circ}$ T-peel technique. Each seal sample was cut into $25 \mathrm{~mm}$ wide and $35 \mathrm{~mm}$ long strips to fit the Shimadzu tensile grips (Fig. 3b). The sealed strips were clamped and equidistantly spaced $25 \mathrm{~mm}$ apart, according to ASTM standard F88 
(2015). The pouches were filled with compressed air to examine the compression strengths. The Shimadzu AGS-10kN universal testing machine was used for this case (Fig. 3c).

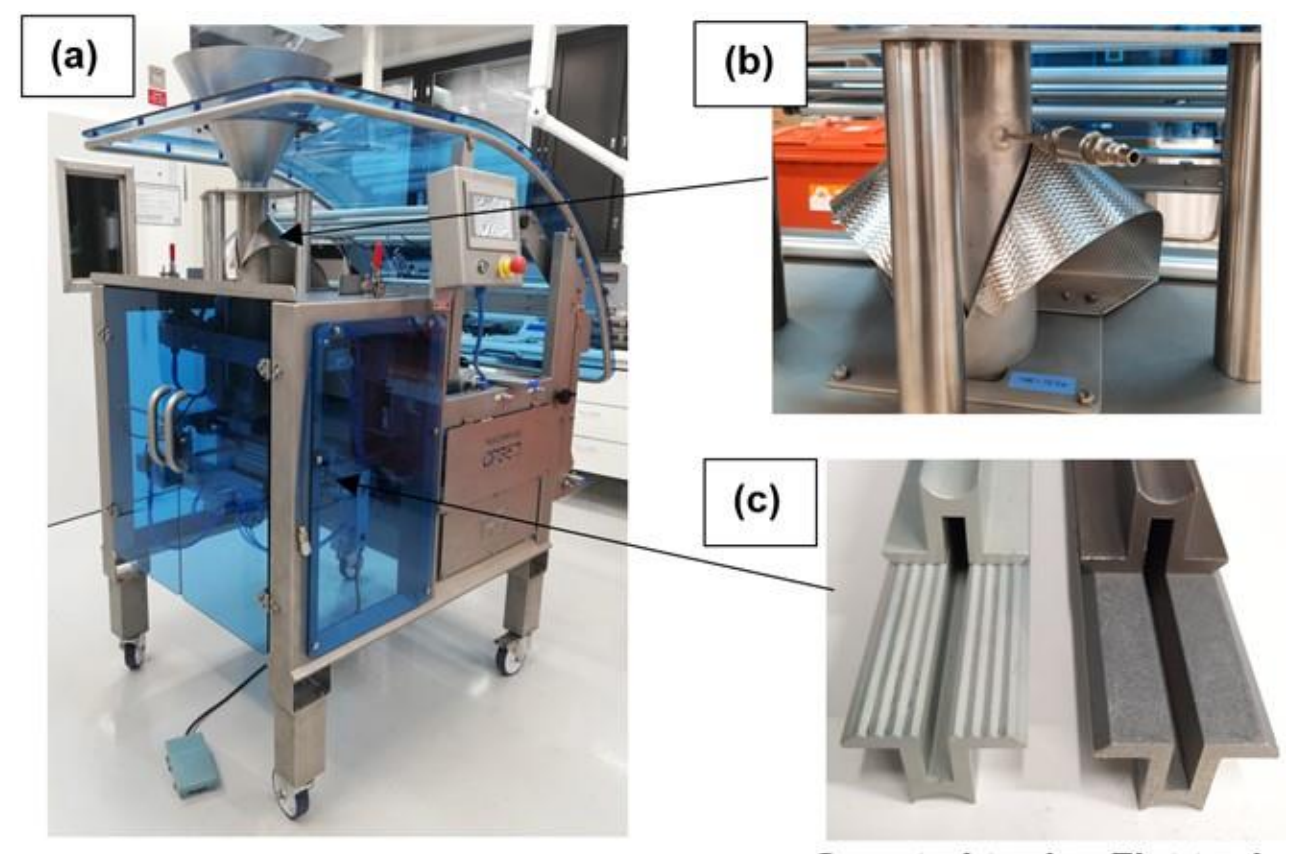

\section{Serrated tool Flat tool}

Fig. 2. The components and VFFS machine used: (a) the VFFS GKS-Compack CP350 Plus; (b) the forming shoulder; and (c) the sealing tool profiles

Table 2. Surface Pressure Calculations for the Sealing Tools

\begin{tabular}{|c|c|c|c|c|}
\hline & $\begin{array}{c}\text { RDM } \\
\text { Laboratory }\end{array}$ & $\begin{array}{c}\text { GKS VFFS } \\
\text { Length Seal }\end{array}$ & \multicolumn{2}{|c|}{$\begin{array}{c}\text { GKS VFFS Horizontal } \\
11 \mathrm{~mm} \text { Sealing Tools }\end{array}$} \\
\hline Tool Name & $\begin{array}{c}\text { Flat heat tool } \\
\text { bar }\end{array}$ & $\begin{array}{c}\text { Longitudinal } \\
\text { length sealer }\end{array}$ & Serrated tool & Flat tool \\
\hline Force $(\mathrm{N})$ & 2588 & 1256 & 2356 & 2356 \\
\hline Surface area $\left(\mathrm{mm}^{2}\right)$ & 6096 & 1920 & 7616 & 6160 \\
\hline Pressure (bar) & 4.2 & 6.5 & 3.1 & 3.8 \\
\hline
\end{tabular}

The seal strength evaluation was conducted according to the guidelines in ASTM standard F88 (2015). Before testing, the samples were allowed to age in airtight zip lock bags for at least $48 \mathrm{~h}$ to achieve the necessary chemical stabilization in the sealant layer. Initially, the samples were pretested at a constant rate $(v)$ of $50 \mathrm{~mm} / \mathrm{min}$ to the point they reached $0.2 \mathrm{~N}$ to remove slack from the samples. The machine then pulled at a constant rate of $300 \mathrm{~mm} / \mathrm{min}$ until a $2 \%$ break detection. The seal strength was then recorded. The compression test was conducted with similar parameters and the maximum force required to burst the pouch was recorded. The prepared sample sizes for both the seal and compression strength tests were six.

The surface texture of the paper-based material was analyzed using a Keyence VR 3200 (Keyence Corporation of America, Elmwood Park, NJ) 3D-profilometery device. The surface roughness of the pillow bags was evaluated to understand the effect of the bending angle and surface texture of the forming shoulder as the material passed over the forming shoulder. 

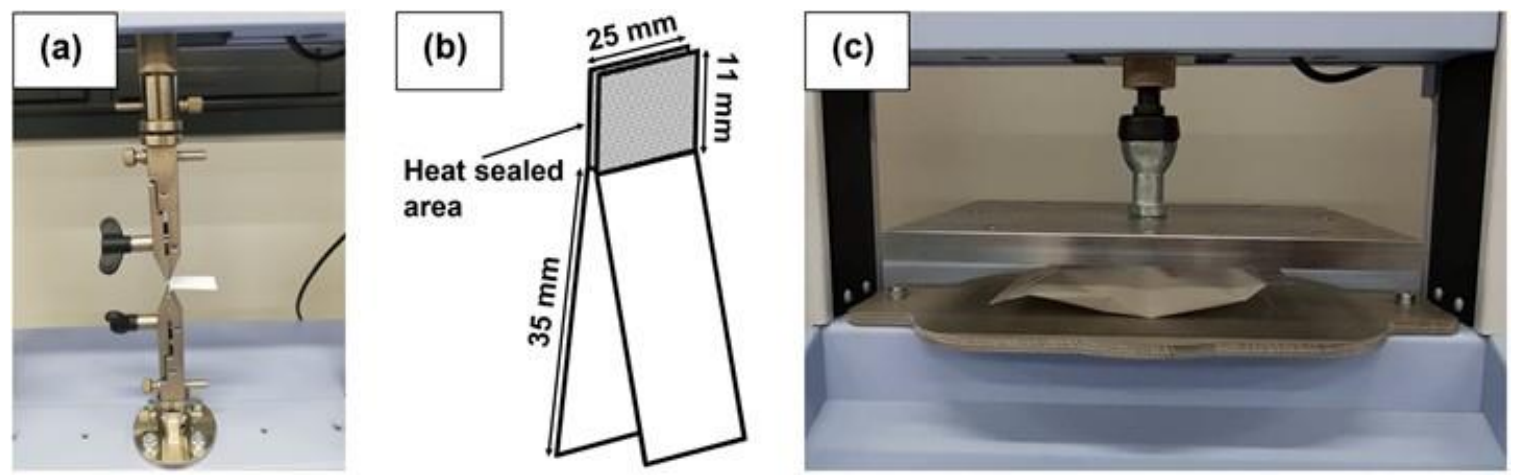

Fig. 3. The experimental setup: (a) Peel test for seal strength test, (b) schematic design of the peel and (c) compression test for compression strength test for the pouches

Eight pillow bags were analyzed to measure the surface topography of the pillow bags, and $80 \mathrm{~mm} \times 80 \mathrm{~mm}$ of the surface area was recorded. The system scanned in the moving direction of the bag. The samples were measured at $12 \mathrm{x}$ magnification in a cross directional scan. Two primary surface roughness parameters were recorded, i.e., the $R_{\mathrm{a}}$ (average roughness value) and $R_{\mathrm{z}}$ (highest roughness value) from the profilometer. These values are essential to understand wrinkles that are caused due to the forming shoulders and for future development.

\section{RESULTS AND DISCUSSION}

\section{Laboratory Heat Sealer}

An RDM Laboratory heat sealer was initially used to investigate the necessary operating window for the paper-based material. A preliminary test showed that the minimum sealing temperature for a sufficiently tight and leak-proof seal was $90{ }^{\circ} \mathrm{C}$ and the maximum sealing temperature was $220^{\circ} \mathrm{C}$. The minimum required dwell time was found to be $0.4 \mathrm{~s}$ at a sealing temperature of $100{ }^{\circ} \mathrm{C}$.

The plot of the seal strength versus the various sealing temperatures at a dwell time of $2 \mathrm{~s}$ with a sealing pressure of 5 bar is shown in Fig. 4. The peel forces only demonstrate the first peel, and the error bars indicate the standard deviation. The variations in the errors are due to the delamination of the paper material. The peeling behavior was found to be inconsistent, as the material cracked between the sealant layer and the paper material.

From the plot, it can be visualized that the sealing began at a temperature of $80{ }^{\circ} \mathrm{C}$ for the Paper $90+30 \mathrm{PE}$ sample, whereas the Paper $70+15$ PE sample sealed at a temperature of $90{ }^{\circ} \mathrm{C}$. At this stage, the sealant layers of both the materials just started to exceed their melting point as highlighted in the orange zoned area. During the peel test, the sealing layer showed minor delamination since the strength of the seal was lower than the strength of the sealant layer (Yuan and Hassan 2007). As the temperature increased, the seal strength increased in a linear fashion. At a sealing temperature of $120{ }^{\circ} \mathrm{C}$, the seal strength became relatively stable and permanently ranged from $11 \mathrm{~N}$ to $13 \mathrm{~N}$ throughout the remainder of the peel test. This led to a similar conclusion made by Stehling and Meka (1994), where the strength became stable at higher temperatures, which led to platen temperatures. The maximum sealing temperature reached for the Paper $70+15 \mathrm{PE}$ material was $220{ }^{\circ} \mathrm{C}$, whereas it was $190{ }^{\circ} \mathrm{C}$ for the Paper $90+30 \mathrm{PE}$ material. Above these corresponding temperatures, the paper-based material started to turn brown. For the plastic 
reference material, the first noticeable seal was at $110{ }^{\circ} \mathrm{C}$ and the maximum temperature was $140{ }^{\circ} \mathrm{C}$. At a sealing temperature greater than $140^{\circ} \mathrm{C}$, the Plastic Ref. material started to turn coarser and shrink around the sealing area. This was caused by the relaxation of the orientated molecular chains and the crystalline fraction of the OPP after the sealing layer had cooled and recrystallized (Hauptmann et al. 2021).

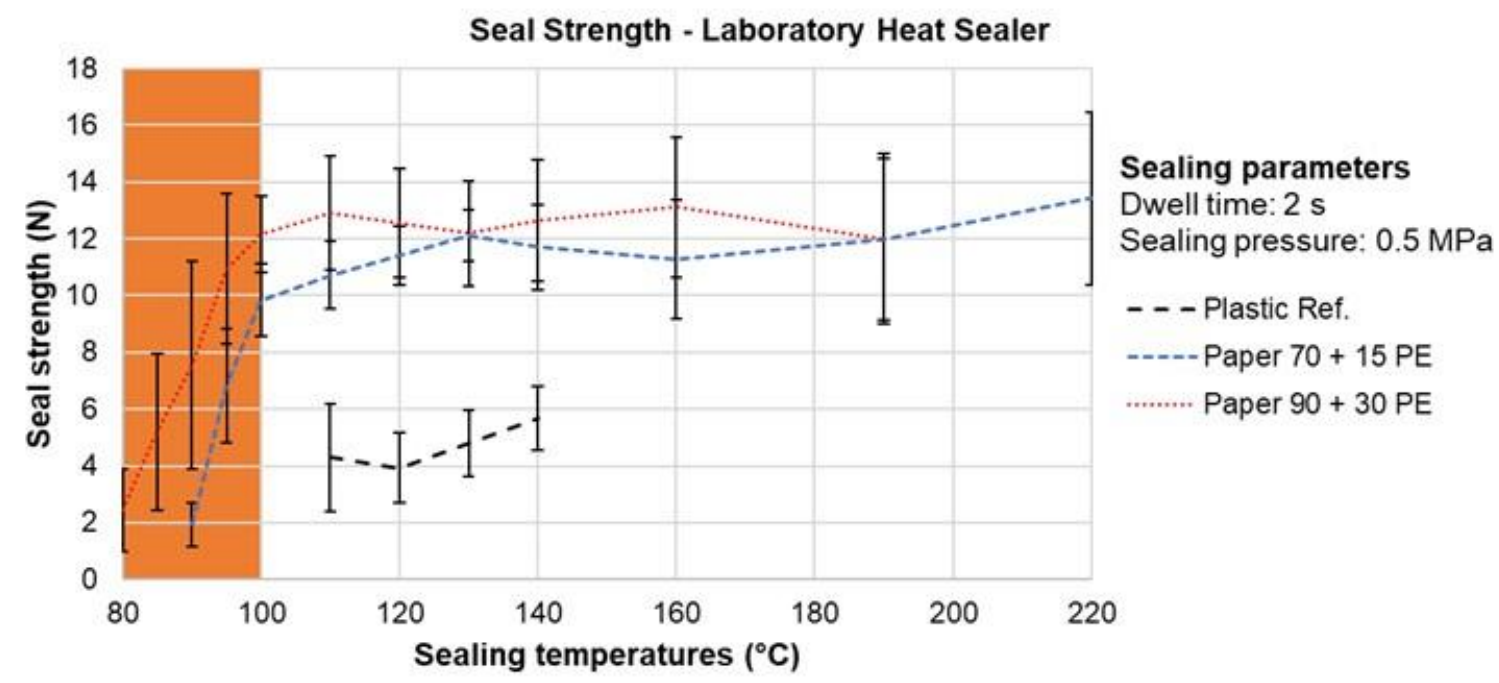

Fig. 4. Seal strength comparison of the studied materials at different sealing temperatures with a fixed dwell time and sealing pressure

The effect of the seal strength with various sealing pressure and temperature values at a fixed dwell time for the paper-based material samples was investigated. The maximum sealing temperature taken as the platen pressure for the seal strength was found was 100 ${ }^{\circ} \mathrm{C}$. The seal strength was relatively stable at each individual sealing temperature, and the trend between the sealing temperature and the pressure was found to be linear (Fig. 5). The first observable seal was at 3 bars, at the minimum sealing temperature of $80{ }^{\circ} \mathrm{C}$. Below 3 bars, the sealant layer did not have sufficient pressure for the entanglement of the polymer chains, regardless of the temperature. Therefore, it can be similarly concluded that the paper-based material showed no considerable change in seal strength with a varying sealing pressure.
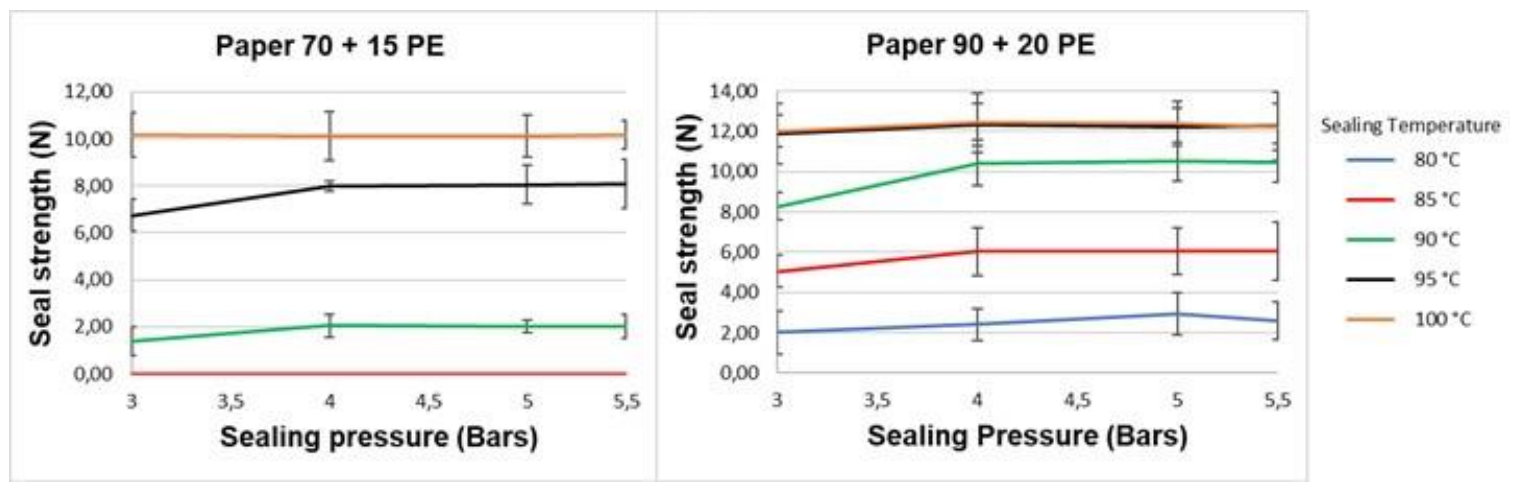

Fig. 5. The effect of the seal strength with various sealing pressure and temperature values at a fixed dwell time of $2 \mathrm{~s}$ for the Paper $70+15$ PE and Paper $90+30$ PE samples 


\section{Peel Seal Strength and Failure Modes Using Vertical Form Fill Seal (VFFS)}

Based on the results obtained from the laboratory heat sealer, a sealing pressure of 5 bar was found to be optimal to examine the effects on the seal strength using a VFFS machine. The effect of the sealing temperature and dwell time on the seal strength with different sealing tool profiles is presented in Fig. 6 . The seal strengths presented in the plots are based on the force required to make the initial peel. The Plastic Ref. material displayed an easy peel phenomenon at sealing temperature up to $110{ }^{\circ} \mathrm{C}$ with the serrated tool. At a sealing temperature of $120^{\circ} \mathrm{C}$ or greater, the seal strength was found to be relatively stable, especially with the Paper $70+15$ PE material. This occurred because there was complete melting and flow of the PE between the sealing layers. When the PE cooled and crystallized, the chains became entangled and behaved as a single layer. This is the effect explained by Theller (1989), and it accounts for the effect of the increasing microBrownian movement as the temperature increases. This is associated with the increased depth of diffusion of the polymer chains, which eventually leads to a higher peel force. A similar scenario can be seen for the flat sealing tool.

As a general observation, in comparison to same sealing tool profiles, the Paper 90 +30 PE material had a slightly higher seal strength compared to the Paper $70+15$ PE material with the same sealing temperature and dwell time ranges. This was the result of a thicker sealant layer in the Paper $90+30$ PE material. The thicker sealant layer resulted in additional entanglement of the polymer chains. Therefore, upon cooling, the final recrystallisation of the polymer chains created a strong entanglement of polymers (Hauptmann et al. 2020). The serrated tool profile resulted in a slightly lower seal strength than the flat tool due to the localized shear stress, which might have caused minor damage to the paper material. Additionally, the tool surface consists of a unique design which creates dynamic shear stress and promotes perpendicular alignments of the polymer chain orientations (Mergenhagen 1991). Instead, there are possible voids in the sealant when flat sealing tool is used.

Regardless of the sealing tool profile, both the Paper $70+15$ PE and Paper $90+30$ PE materials had zero or a very low sealing strength at a sealing temperature of $100{ }^{\circ} \mathrm{C}$ and a dwell time of $0.5 \mathrm{~s}$. At this temperature range, the material displayed easy peel properties, no observable seal distortion, and no failure in the laminated structure. However, this temperature range is not practically feasible because the sealing layer does not have sufficient strength to hold the product falling from the dispensing dozer. Therefore, to prevent the opening of the seal during production, the minimum dwell time plateau at a sealing temperature of $100{ }^{\circ} \mathrm{C}$ should be greater than $1 \mathrm{~s}$.

Delamination and tearing failure of the sealant were first observed at a sealing temperature of $110^{\circ} \mathrm{C}$ from a dwell time of $1 \mathrm{~s}$ and greater. This kind of failure was attributed due to higher seal strength of the sealant layer as compared to the strength paperbased material. The concentration of the failure was primarily found on one side of the film, as shown in the failure modes in Fig. 7. The Paper $90+30$ PE material delaminated more than the Paper $70+15$ PE material because the sealant layer was thicker, creating a higher stress concentration with the polymer chains. The seal strength was substantially enhanced as the sealing temperature increased; however, fluctuation in the seal strength was constantly seen for both paper-based materials. At sealing temperatures greater than $120{ }^{\circ} \mathrm{C}$, unacceptable tearing failures were observed with both sealing tools. 

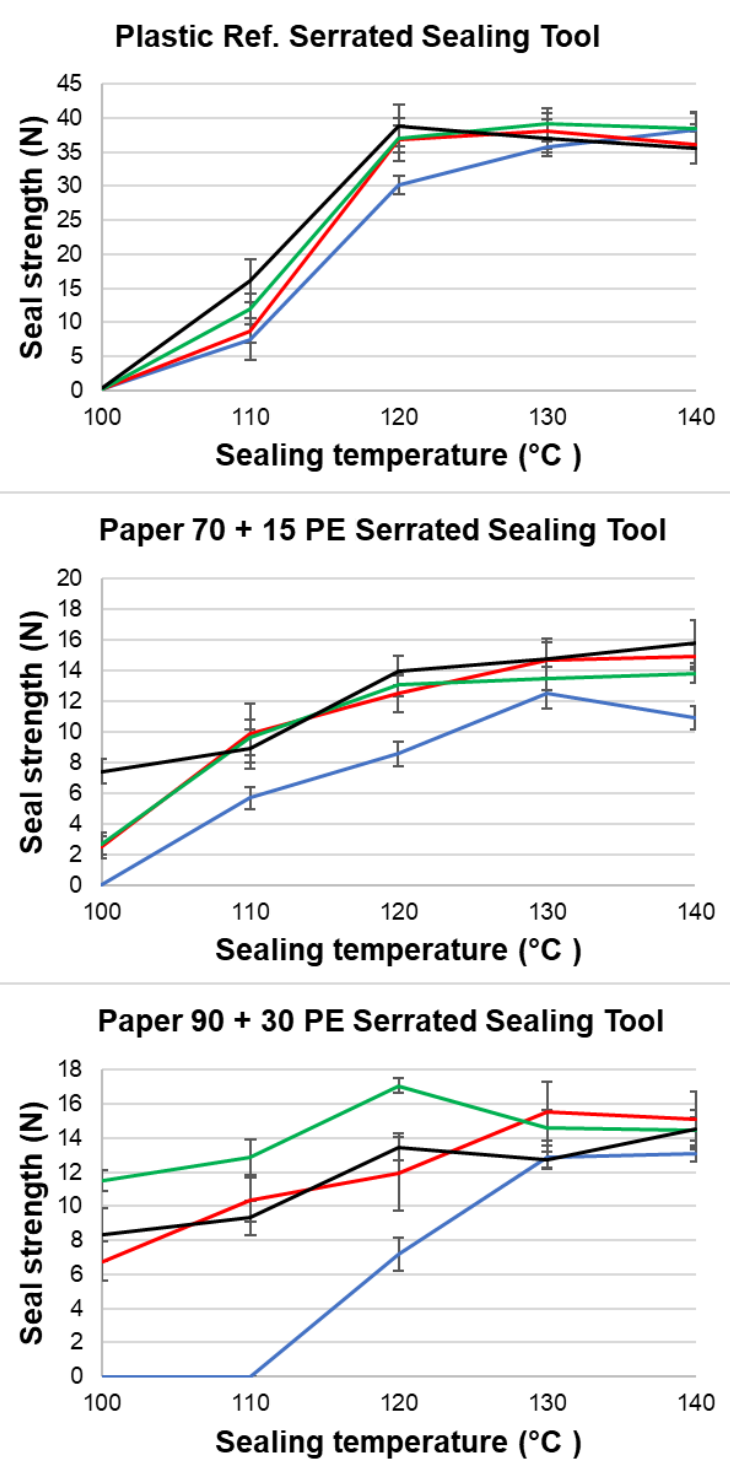

Plastic Ref. Flat Sealing Tool
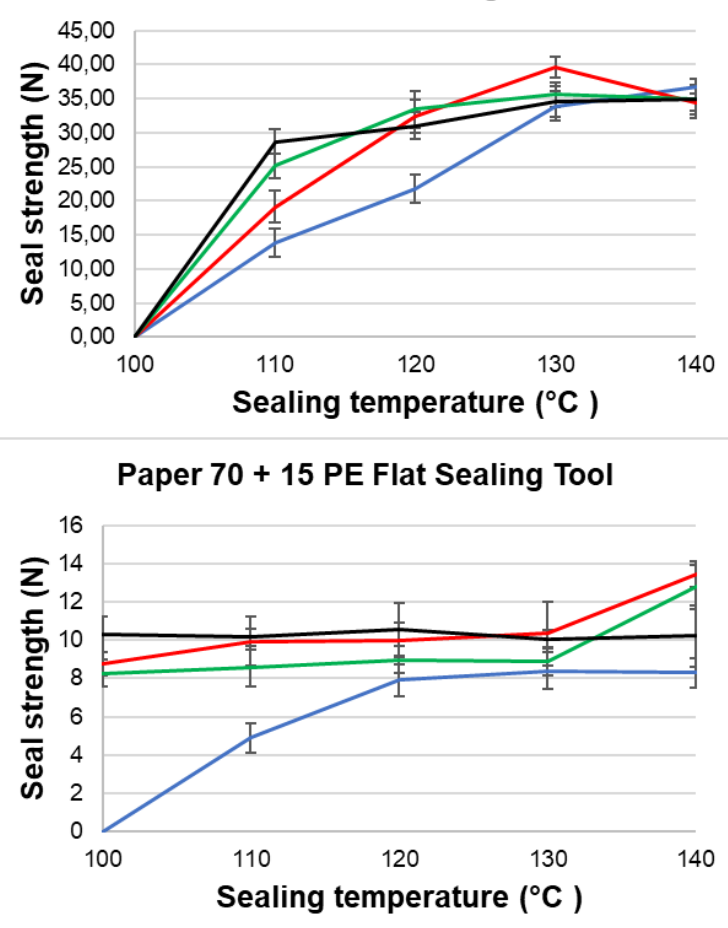

Paper $90+30$ PE Flat Sealing Tool

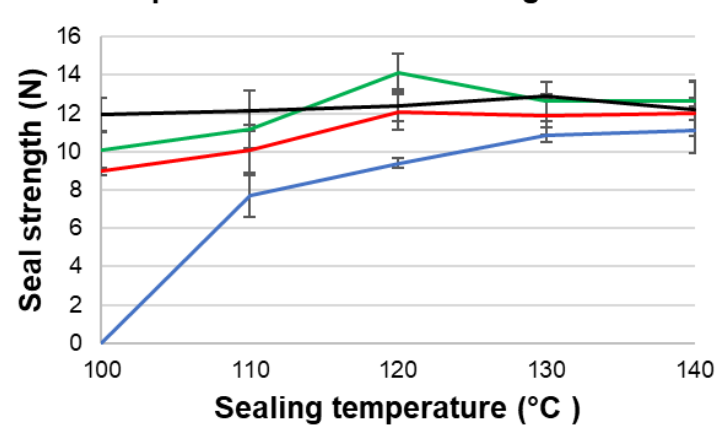

$-0.5 \mathrm{~s}-1 \mathrm{~s}-1.5 \mathrm{~s}-2 \mathrm{~s}$

Fig. 6. Seal strength comparison of the studied materials at different sealing temperatures with a fixed dwell time and sealing pressure

During the peel test, the Plastic Ref. material experienced elongation at sealing temperatures greater than $120^{\circ} \mathrm{C}$. However, for the paper-based material, no material or sealant elongation was observed. It is expected that the moisture content influences the seal strength of the material. If the moisture content is increased, then there will be an increase in the elongation and a reduction in the tensile strength (Hauptmann et al. 2020). In this experiment, the moisture content was reduced by nearly $35 \%$ during the production trials, which made the material brittle and easy to tear. For future studies, the effect of the moisture content on the flexible paper material will be studied, as well as its impact on the runnability. 

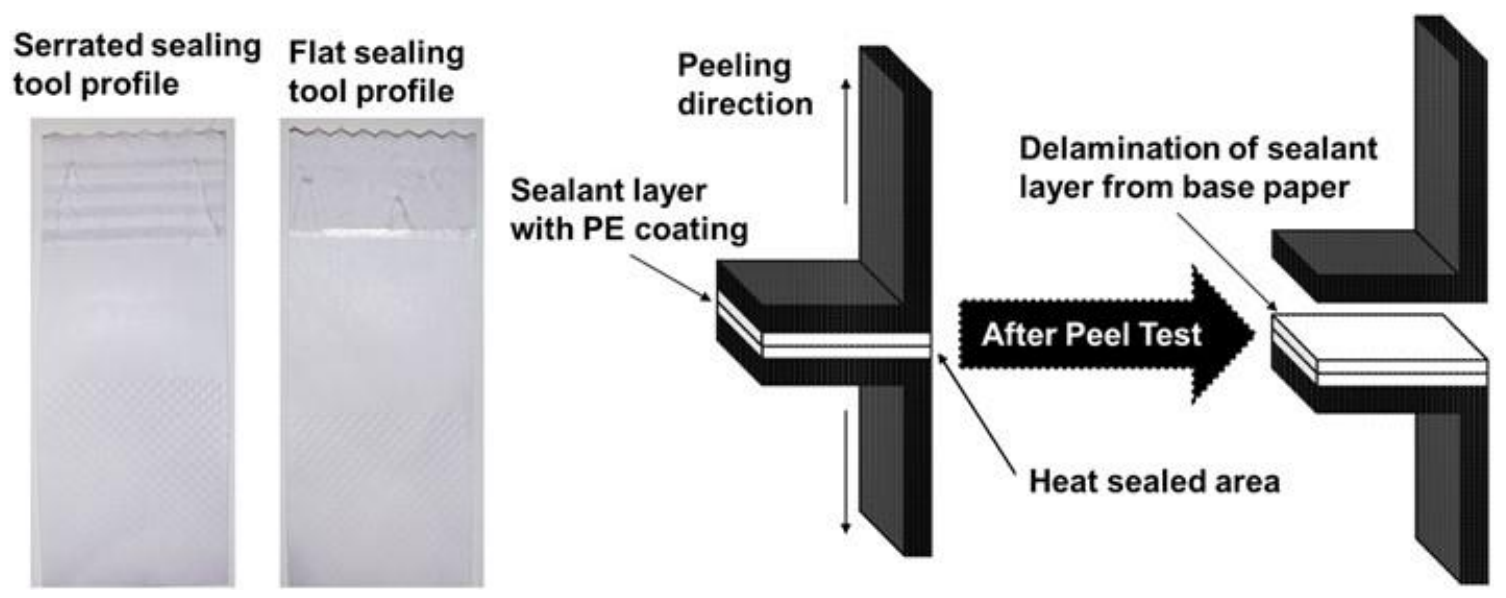

Fig. 7. Delamination of the Paper $90+30 \mathrm{PE}$ material at a sealing temperature of $140{ }^{\circ} \mathrm{C}$ with the mode of failure, as per ASTM standard F88 (2015)

\section{Compression Strength and Failure Modes Using Vertical Form Fill Seal (VFFS)}

The pillow bags were filled with a constant air flow to evaluate the compression strength of the pouches. The effect of compression strength at various sealing temperatures and dwell times is presented in Fig. 8. It was discovered that the pouches could handle high compressive forces. This suggests that the pouches should be able to withstand an impact during freefall when filled with products; however, this will be investigated in future studies.

During the compression strength test, regardless of the sealing tool profile, several pillow bags had noticeable air leakage from the horizontal seam. This led to the conclusion that the paper-based pouches were not $100 \%$ airtight. The presence of a leak generated a stress concentration around the area that influenced the bursting effect. Future studies will investigate the tightness of the seal by using a dye penetration test, e.g., standardized dyed ethanol or rhodamine dye. In contrast, the Plastic Ref. material pouches were airtight with no signs of air-leaks. The thermoplastic material had approximately three times the strength with a serrated sealing tool and double the strength with a flat sealing tool in comparison to the paper-based materials.

The majority of the compression strength results showed a substantial increase as the temperatures increased. A rapid transition phase in the compression strength was observed at a sealing temperature of 110 to $130{ }^{\circ} \mathrm{C}$ for most samples. Unlike the Paper 70 $+15 \mathrm{PE}$ material, at a high sealing temperature of approximately $140{ }^{\circ} \mathrm{C}$, a possible reduction in compression strength was observed in the Paper $90+30$ PE material. It is very likely that at this temperature range, the Paper $70+15$ PE material did not yet reach a plateau temperature. It is possible that the Paper $90+30$ PE laminate layer was completely molten, with the possibility of a shear flow under pressure, which could lead to seal distortion at a sealing temperature of $130{ }^{\circ} \mathrm{C}$. Additionally, it was expected that the flat sealing jaw could have created a larger surface contact area, which resulted in strong entanglement of the melted laminate layer.

The variation of dwell time had a major effect on the compression strength of the paper-based materials. At a dwell time greater than $0.5 \mathrm{~s}$, it was observed that the compression strength became stable between sealing temperatures of 110 to $130{ }^{\circ} \mathrm{C}$, but a sudden drop was observed in the Paper $90+30$ PE material. At this temperature range, 
there was enough heat that reached and melted the sealant layer. As mentioned earlier with the seal strength test, this enriched the polymer chains to diffuse across each other and created a strong entanglement of the melted laminate layer.

From this study, it is concluded that there were no considerable differences in the compression strength between the serrated and flat sealing tool profiles. However, the materials sealed with the serrated sealing tool profile had a slightly lower compression strength compared to the flat sealing tool. It is reasonable to assume that the $90^{\circ}$ serrations would reduce channels for any possible leakages, which resulted in a higher compression strength. However, the multiple serrations had side effects affecting the paper-based materials (Mergenhagen 1991). The flat sealing tool resulted in the bag bursting more often, and the serrated tool resulted in severe damage and the center of the bag bursting more often. The results of the compression strength tests of the pillow bags are shown in Fig. 9.
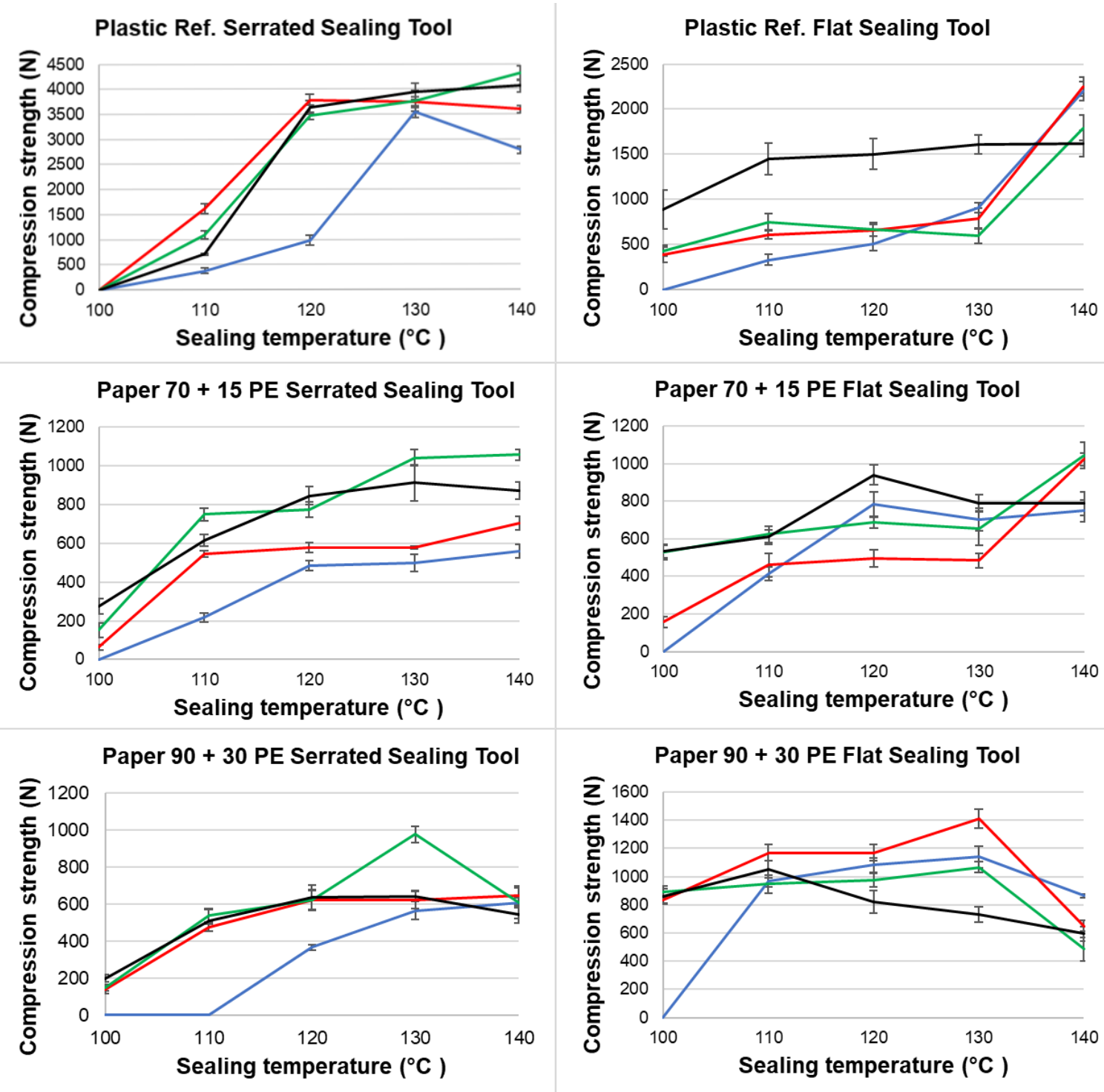

$$
-0.5 \mathrm{~s}-1 \mathrm{~s}-1.5 \mathrm{~s}-2 \mathrm{~s}
$$

Fig. 8. Compression strength of the studied materials at different sealing temperatures with a fixed dwell time and sealing pressure 

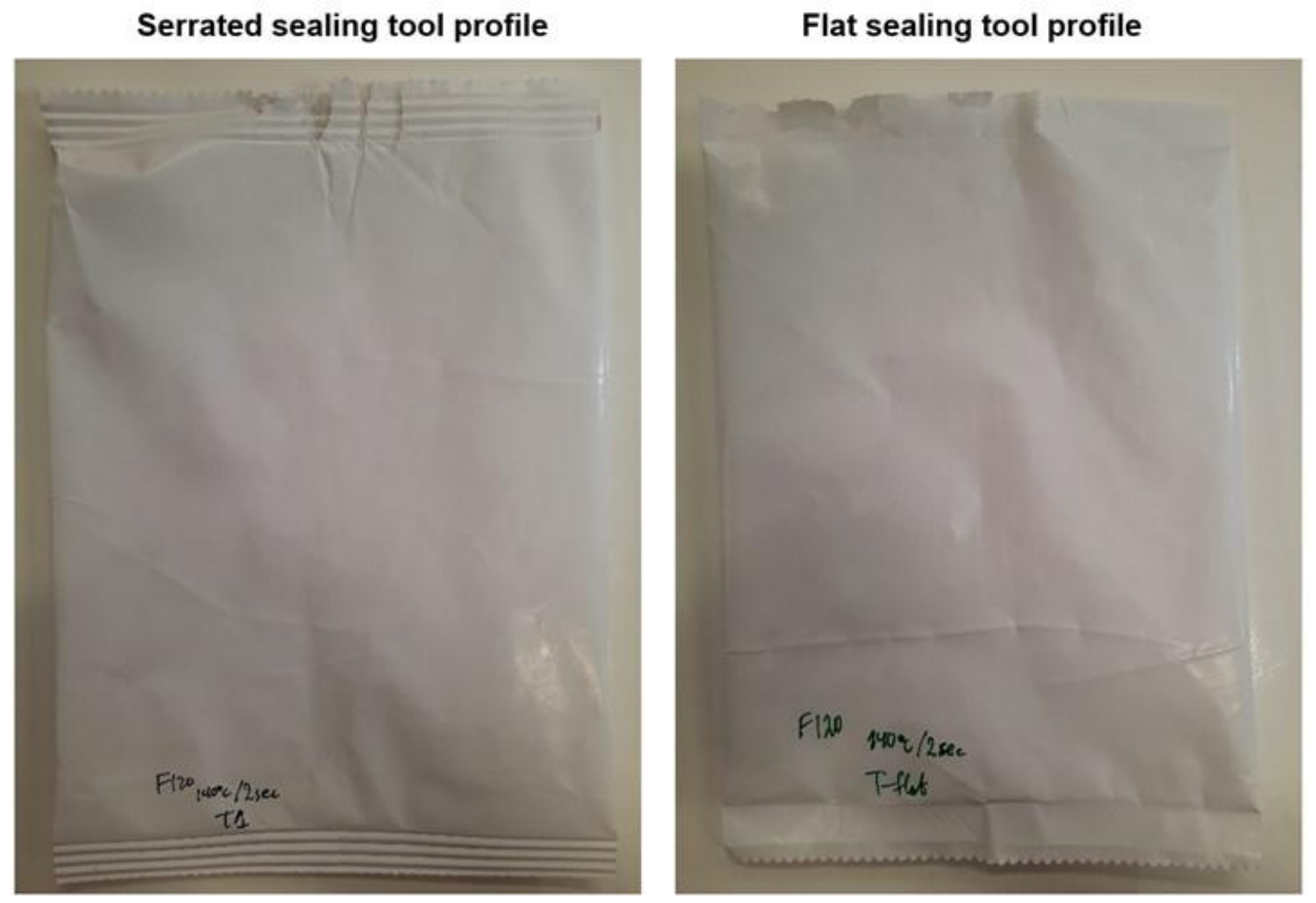

Fig. 9. Compression tested bag samples of the Paper $90+30 \mathrm{PE}$ material at a sealing temperature of $140^{\circ} \mathrm{C}$ and a dwell time of $2 \mathrm{~s}$

\section{Runnability of Paper-based Material with a Vertical Form Fill Seal (VFFS) Machine}

As the development of a flexible paper-based material became the center of focus, several important machine mechanisms and tooling sets needed to be further developed. A change in material specifications can greatly influence the performance of the packaging machines. There are several issues and constraints when it comes to the runnability of paper-based materials in the current VFFS machines. These include film web buckling, friction of the material flow in the forming tube, and major wrinkling of the material due to the forming shoulder.

The buckling of the web film is caused by the misdirection of the web transportation and tensioning. During the transportation of the film over the rollers, buckling was seen due to shear forces. These were caused by web tensioning and misalignment (Fig. 10). The movement of the web film is controlled sideways by the reel adjuster to make sure the edges of the film are overlapped in the forming tube to form a vertical seam.

As the film web was tensioned, the web buckling was noticeably reduced. However, this caused excessive frictional forces between the rollers and the film web. The transport speed was regulated to reduce the web buckling; however, there was no considerable difference. One minor solution was to increase the tensioning and tightening of the film web using the adjustable pressure control valves from the pneumatic unit. This considerably reduced the wander of the film web and major web buckling. Another possibility is to implement an electronic control unit to monitor the film handling system. This could improve the transvers motion of the spindle roll to match the width of the forming shoulder. 
The forming tube and shoulder are two important components in VFFS machines. The forming shoulder shapes the film for the forming tube. The design complexity of the forming shoulder influences the film as the belt tension forces the film. It has been shown that the forming shoulder is responsible for the final quality of the formed bags. In this experiment, minor obstacles were seen when the film was driven over the forming shoulder due to the geometry and material surface. Figure 11 shows a material cut caused by the sharp edges, the run-in angle, and the narrow fillet of the forming shoulder. As the material flows over the forming shoulder, it creates a distortion along the bending curve, which eventually causes wrinkling on the surface of the material.

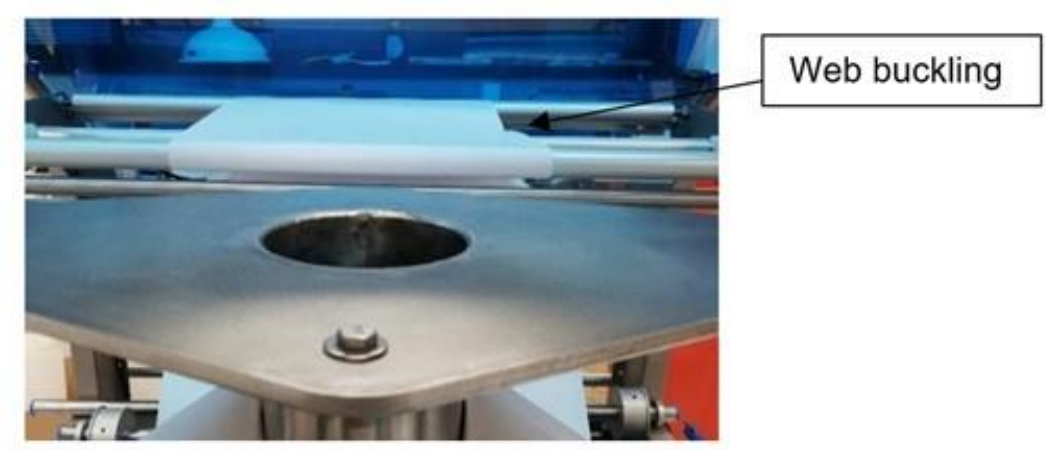

Fig. 10. Web buckling of the Paper $70+30$ PE material during the production run

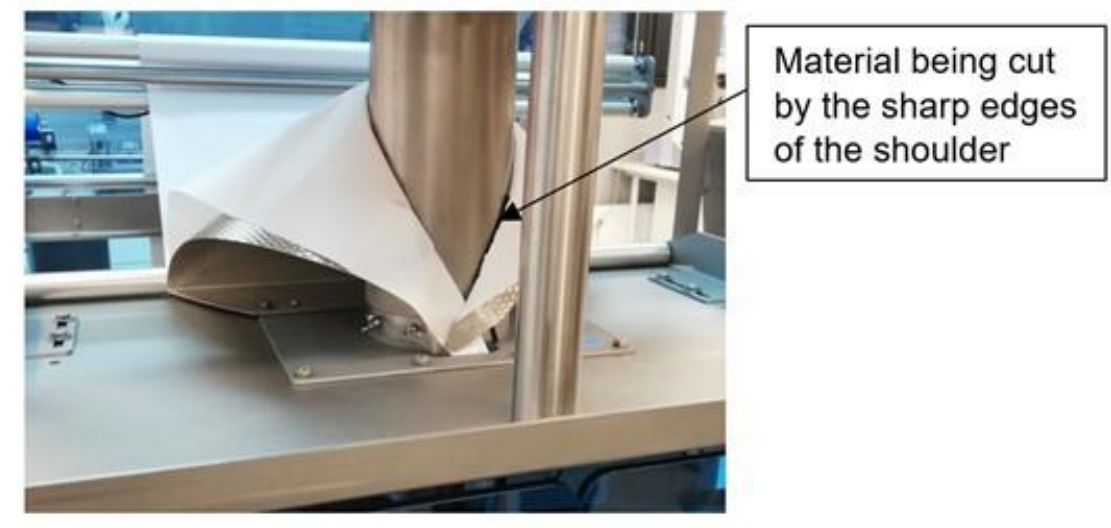

Fig. 11. Material being cut due to the sharp edges of the forming shoulder

High amounts of wrinkling result in quality loss of the product (Hishinuma 2009). Figure 12 shows a pillow bag made from the Paper $70+15$ PE material after it has passed over the forming shoulder. The wrinkling can be clearly seen with the naked eye. The surface quality roughness, measured in $\mu \mathrm{m}$, was analyzed using a $3 \mathrm{D}$ profilometer to investigate the effect of the wrinkles on the material (Leminen et al. 2015c).

The profilometer test results displaying the 3D roughness intensity for the Paper 70 +15 PE and Paper $90+30$ PE materials are shown in Fig. 13. The location of the images chosen were in the center of the bag. The number of wrinkles seen are greater in the cross direction compared to the machine direction. From examining the pillow bag samples and the images, the roughness on the edges was generally greater, whereas the wrinkles were generally on the entire surface of the bag. The wrinkles and waviness on the surface were found on every bag. 


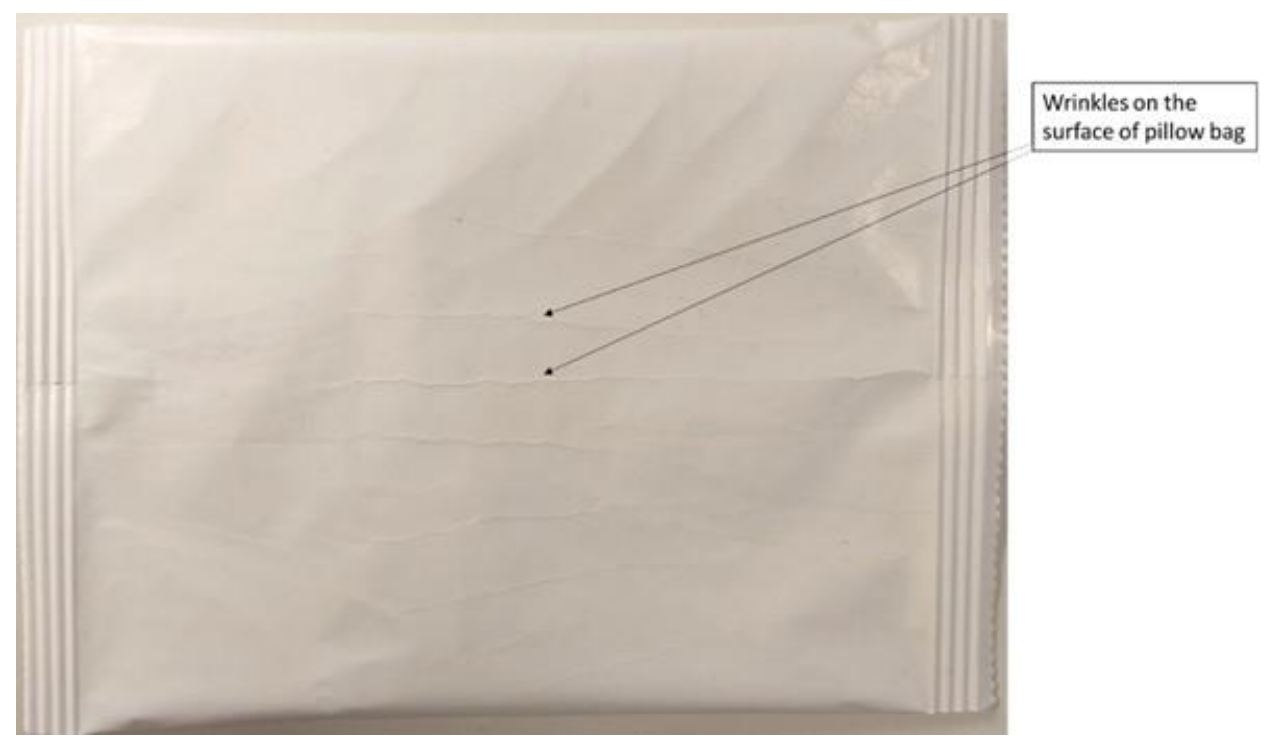

Fig. 12. Wrinkling seen on the surface of a Paper $70+15$ PE pillow sample bag
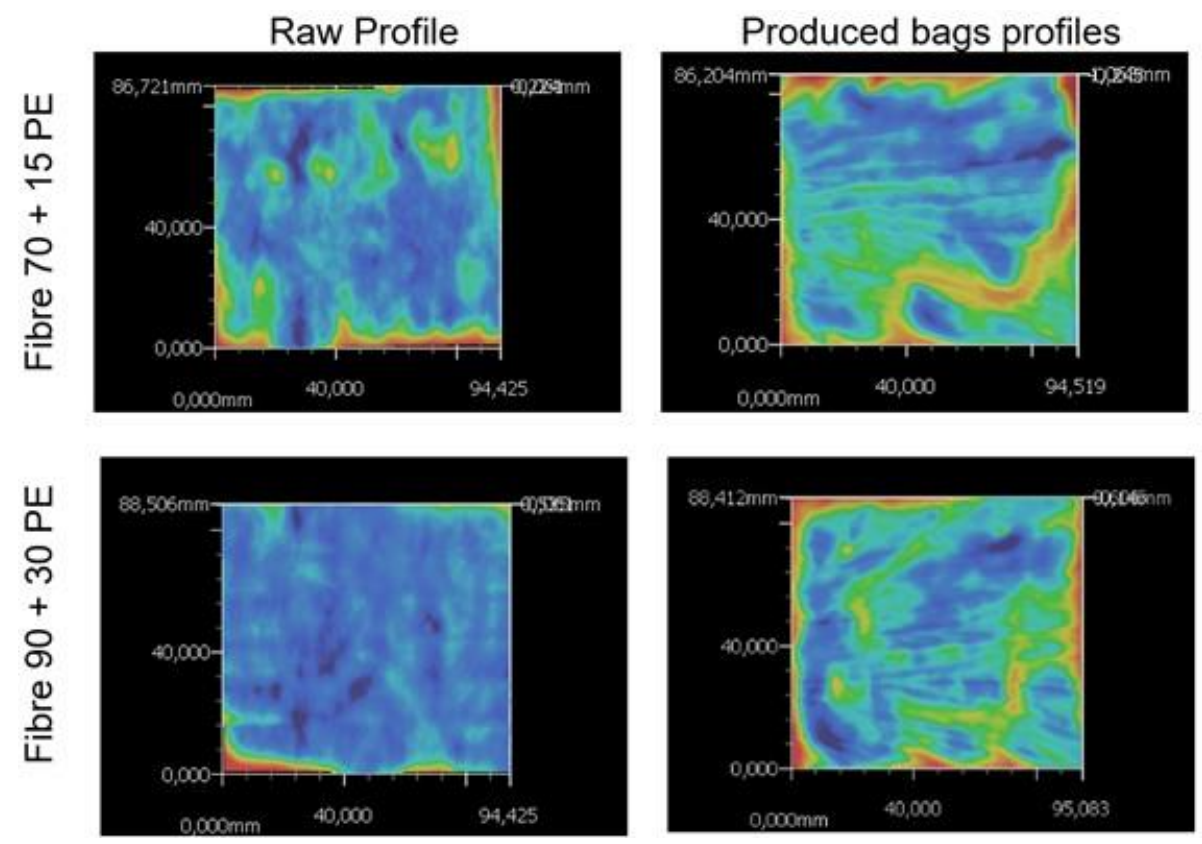

Fig. 13. Surface roughness profile images of Paper $70+15$ PE and Paper $90+30$ PE materials

Next, 50 multiline profiles were equally spaced to measure the surface roughness across the pillow bag. They were analyzed and presented in the form of bar graphs showing the average roughness $\left(R_{\mathrm{a}}\right)$ and the average peak roughness $\left(R_{\mathrm{z}}\right)$ (Fig. 14). The initial roughness values of the raw materials were a relatively low and had a smooth texture. It

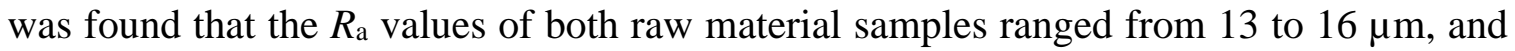
the $R_{\mathrm{z}}$ values ranged from 50 to $90 \mu \mathrm{m}$. After being passed over the forming shoulder, both the $R_{\mathrm{a}}$ and $R_{\mathrm{Z}}$ values of the samples were found to be higher compared to the raw samples by $405 \%$ for the Paper $70+15$ PE material and $450 \%$ for Paper $90+30$ PE material. The Paper $90+30 \mathrm{PE}$ material had a higher roughness values as the thickness of the material increased the stiffness and reduced the flexibility that allowed it to bend over the forming shoulder. 

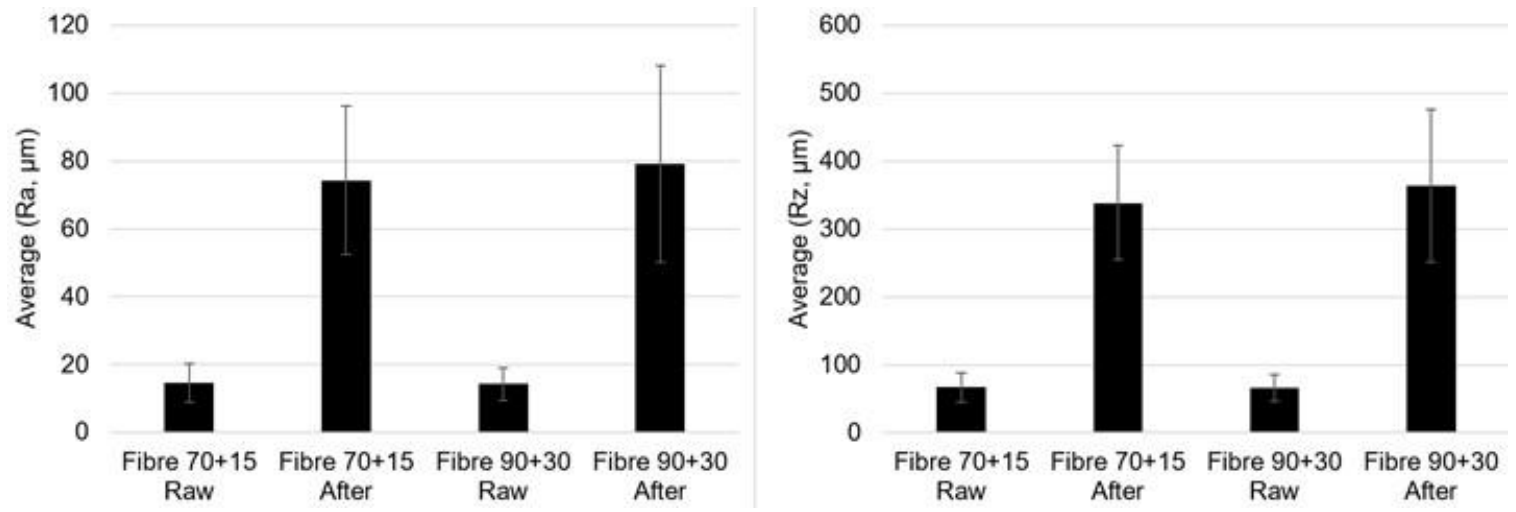

Fig. 14. $R_{\mathrm{a}}$ and $R_{\mathrm{z}}$ values of pillow bags measured by the 3D profilometer

Lastly, as the film is pulled through the forming tube by the transport belt, friction is created. With time, the frictional force generates heat within the forming tube and the paper material. It was realized that after producing approximately 15 pillow bags, the temperature in the forming tube (adjacent to the belt transport) had been elevated by 5.3 ${ }^{\circ} \mathrm{C}$. Therefore, it is possible that this heat further increased the surface friction in the forming tube. The result of this scenario is demonstrated in Fig. 15.

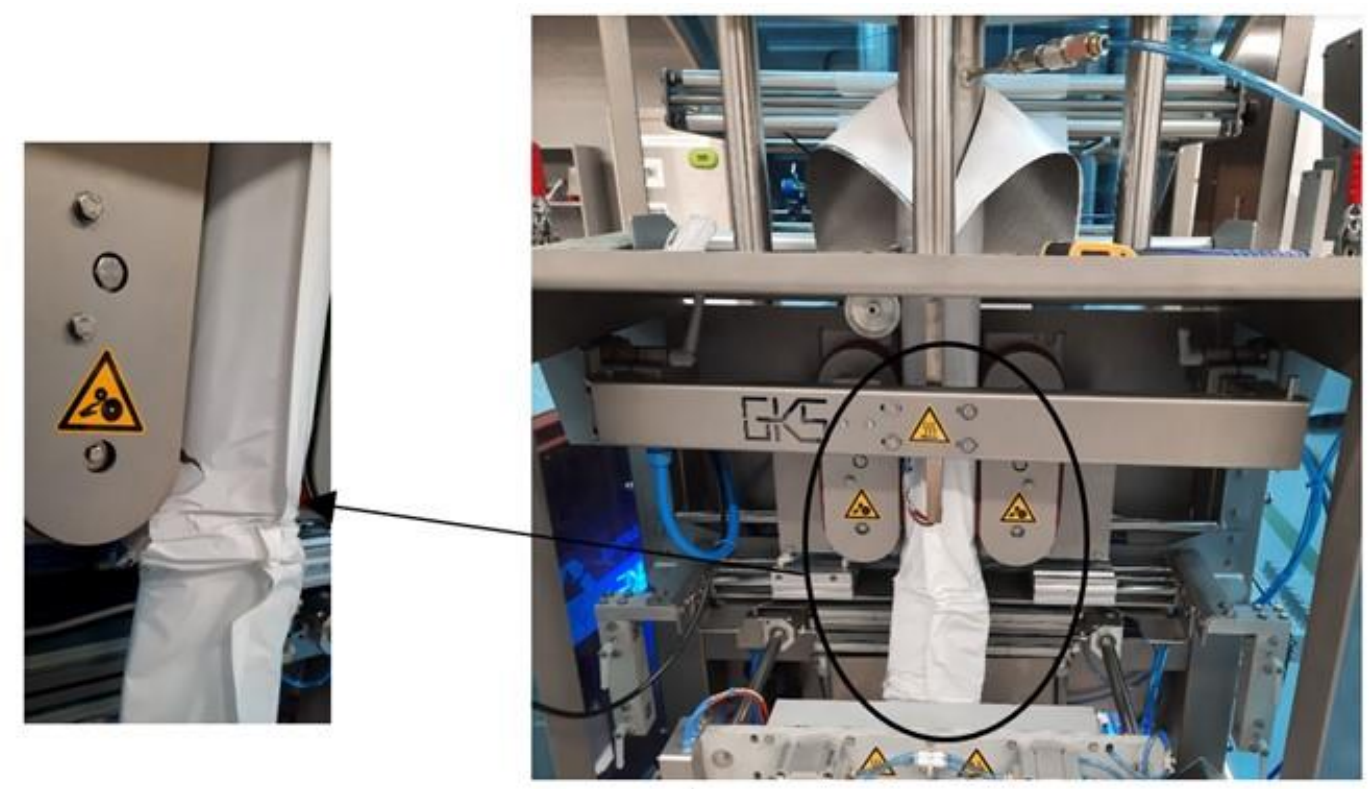

Fig. 15. Frictional interaction caused failure of material transport in forming tube

The frictional interaction between the forming tube, belt, and paper material requires further investigation to understand the effect the belt velocity, friction, and contact temperature has on the runnability of the material. One solution is to scale this scenario to laboratory scale and measure the coefficient of friction, sliding friction, and impact with additional heat.

Previous studies have used complex mathematical modelling, e.g., the finite element method to design and model next generation forming shoulders (Desoki et al. 2010). Others have utilized Euler's theory to design the forming shoulder and material 
passing around the forming tube (Matthews et al. 2011). Future studies will further investigate and develop solutions to reduce the wrinkles and improve the material flow as well as further investigate the optimal bending angle to minimize the formation of wrinkles as the material flows to the tube.

\section{CONCLUSIONS}

1. The process parameters determined by the laboratory heat sealer could be directly transferred to the production device. Thus, the actual test runs were initiated efficiently. The paper-based material was first sealed at a temperature of $90{ }^{\circ} \mathrm{C}$ and was found to be able to handle higher sealing temperatures; up to $220^{\circ} \mathrm{C}$ for the Paper $70+15 \mathrm{PE}$ material and $190^{\circ} \mathrm{C}$ for the Paper $90+30 \mathrm{PE}$ material before the paper turned brown. The Plastic Ref. material started to seal at a sealing temperature of $100{ }^{\circ} \mathrm{C}$ and shrank around the sealing tool areas at sealing temperatures greater than $140{ }^{\circ} \mathrm{C}$.

2. The paper-based material showed no considerable changes in seal strength with varying amounts of sealing pressure. Therefore, the sealing pressure had nearly no effect on the seal strength as far long as there was sufficient pressure, which was 3 bar.

3. The seal strength of the paper-based materials depended on the thickness. Using a VFFS machine, it was found that the Paper $90+30$ PE material had a higher seal strength than the Paper $70+15$ PE material. The thicker sealant layer created higher interdiffusion of the polymer chains, which created a strong entanglement of polymers upon recrystallisation. On average, the seal strength of the Plastic Ref. material was 3 times higher compared to the paper-based materials.

4. From the peel test, the paper-based material delaminated completely from one side of the film at a sealing temperature of $120^{\circ} \mathrm{C}$. The Paper $90+30 \mathrm{PE}$ material delaminated more than the Paper $70+15$ PE material because the sealant layer was thicker, which created a higher stress concentration with the polymer chains.

5. The compression strength proved that the paper-based pouches could withstand high compressive forces (approximately $500 \mathrm{~N}$ ) at a sealing temperature of $110{ }^{\circ} \mathrm{C}$. However, regardless of the sealing tools, the pouches were not $100 \%$ airtight.

6. The serrated tool profile proved to have a slightly lower seal and compression strength compared to the flat sealing tool. This was due to higher dynamic and localized shear stresses, which caused minor damage to the surface of the paper-based materials.

7. During the production trials, the paper-based materials lost some of their moisture content, which made the material more brittle and easier to tear.

8. Wrinkling was observed on the surface of the paper-based materials due to the sharp fillet edges of the forming shoulder. The surface roughness of the pouches was examined using a 3D profilometer and an increase in roughness of approximately $400 \%$ was observed compared to the raw film.

9. There was high frictional interaction between the paper-based material and the forming tube as the belt pulled the material down. The generated heat further increased the surface friction in the forming tube, which impacted on the runnability. 
10. Flexible paper-based materials have considerable potential for commercial use. Despite the challenges caused by the material properties, they can be used to produce the desired types of bag packages after precise process optimization.

\section{ACKNOWLEDGMENTS}

The authors would like to thank StoraEnso for providing us with the paper-based material. This research was funded by the European Union's Regional Development Fund (ERDF) project KUPARI, project code A74093.

\section{REFERENCES CITED}

Aithani, D., Lockhart, H., Auras, R., and Tanprasert, K. (2006). "Predicting the strongest peelable seal for 'easy-open' packaging applications," Journal of Plastic Film \& Sheeting 22(4), 247-263. DOI: 10.1177/8756087906071351

ASTM F88 / F88M-15 (2015). "Standard test method for seal strength of flexible barrier materials," ASTM International, West Conshohocken, PA.

Desoki, A., Morimura, H., and Hagiwara, I. (2010). "General design of the forming collar of the vertical form, fill and seal packaging machine using the finite element method," Packaging Technology and Science 24(1), 31-47. DOI: 10.1002/pts.919

Dudbridge, M. (2016). Handbook of Seal Integrity in the Food Industry, John Wiley \& Sons, Ltd., Hoboken, NJ,

Hashimoto, Y., Ishiaku, U. S., Leong, Y. W., Hamada, H., and Tsujii, T. (2005). "Effect of heat-sealing temperature on the failure criteria of oriented polypropylene/cast polypropylene heat seal," Polymer Engineering and Science 46(2), 205-214. DOI: 10.1002/pen.20452

Hauptmann, M., Bär, W., Schmidtchen, L., Bunk, N., Abegglen, D., Vishtal, A., and Wyser, Y. (2020). "The sealing behavior of new mono-polyolefin and paper-based film laminates in the context of bag form-fill-seal machines," Packaging Technology and Science 34(2), 117-126. DOI: 10.1002/pts.2544

Hauptmann, M., Bär, W., Schmidtchen, L., Bunk, N., Abegglen, D., Vishtal, A., and Wyser, Y. (2021). "The effect of flexible sealing jaws on the tightness of pouches made from mono-polyolefin films and functional papers," Packaging Technology and Science 34(3), 175-186. DOI: 10.1002/pts.2552

Hishinuma, K. (2009). Heat Sealing Technology and Engineering for Packaging, DEStech Publications, Lancaster, PA.

Ilhan, I., Turan, D., Gibson, I., and Klooster, R. (2021). "Understanding the factors affecting the seal integrity in heat sealed flexible food packages: A review," Packaging Technology and Science 34(6), 321-337. DOI: 10.1002/pts.2564

Leminen, V., Kainusalmi, M., Tanninen, P., Lohtander, M., and Varis, J. (2012). "Effect of sealing temperature to required sealing time in heat sealing process of a paperboard tray," Journal of Applied Packaging Research 6(2), 67-78.

Leminen, V., Tanninen, P., Lindell, H., and Varis, J. (2015a). "Effect of blank holding force on the gas tightness of paperboard trays manufactured by the press forming process," BioResources 10(2), 2235-2243. DOI: 10.15376/biores.10.2.2235-2243 
Leminen, V., Mäkelä, P., Tanninen, P., and Varis, J. (2015b). "Leakproof heat sealing of paperboard trays - Effect of sealing pressure and crease geometry," BioResources 10(4), 6906-6916. DOI: 10.15376/biores.10.4.6906-6916

Leminen, V, Mäkelä, P, Tanninen, P, and Varis, J. (2015c). "The use of chromatic white light 3D-profilometry in the surface quality analysis of press-formed paperboard trays," in: Proceedings of the $25^{\text {th }}$ International Conference on Flexible Automation and Intelligent Manufacturing (FAIM), 23-26 June, Wolverhampton, United Kingdom, pp. 74-81.

Leminen, V., Mäkelä, P., Tanninen, P., and Varis, J. (2015d). "Methods for analyzing the structure of creases in heat sealed paperboard packages," Journal of Applied Packaging Research 7(1), 49-60. DOI: 10.14448/japr.03.0005

Leminen, V., Pesonen, A., Tanninen, P., and Varis, J. (2017). "Effect of elevated heat sealing pressure on the gas tightness of press-formed paperboard trays," BioResources 12(4), 8359-8367. DOI: 10.15376/biores.12.4.8359-8367

Matthews, J., Hicks, B. J., Mullineux, G., Goodwin, J., and Burke, A. (2011). "Modelling the material flow and web tension in the vertical form-fill-seal packaging process," Packaging Technology and Science 24(8), 435-450. DOI: 10.1002/pts.949

Meka, P., and Stehling, F. C. (1994). "Heat sealing of semicrystalline polymer films. I. Calculation and measurement of interfacial temperatures: Effect of process variables on seal properties," Journal of Applied Polymer Science 51(1), 89-103. DOI: 10.1002/app.1994.070510111

Mergenhagen, L. K. (1991). "Performance of thermoplastic polymers as sealants in form/fill/feal flexible packaging applications," in: Search of Excellence: ANTEC 91: Conference Proceedings, Society of Plastics Engineers, Danbury, CT.

Morris, B. A. (2002). "Predicting the heat seal performance of ionomer films," Journal of Plastic Film \& Sheeting 18(3), 157-167. DOI: 10.1177/8756087902018003002

Morris, B. A. (2017). "Heat seal," in: The Science and Technology of Flexible Packaging: Multilayer Films from Resin and Process to End Use, W. Andrew (ed.), Elsevier Ltd., Oxford, United Kingdom.

Mueller, C., Capaccio, G., Hiltner, A., and Baer, E. (1998). "Heat sealing of LLDPE: Relationships to melting and interdiffusion," Journal of Applied Polymer Science 70(10), 2021-2030. DOI: 10.1002/(sici)1097-4628(19981205)70:10<2021::aidapp18>3.0.co;2-a

Mullineux, G., McPherson, C. J., Hicks, B. J., Berry, C., and Medland, A. J. (2007). "Constraints influencing the design of forming shoulders and the use of exact geometry," Strojniski Vestnik - Journal of Mechanical Engineering 53, 478-490.

Pira, S. (2021). "Flexible packaging market trends to 2024," (https://www.smithers.com/services/market-reports/packaging/flexible-packaging-to2024\#: :text=New\%20research\%20from\%20Smithers\%20charts,reaching\%20\%2426 9\%20billion\%20in\%202024), accessed 7 March 2021.

Stehling, F. C., and Meka, P. (1994). "Heat sealing of semicrystalline polymer films. II. Effect of melting distribution on heat-sealing behavior of polyolefins," Journal of Applied Polymer Science 51(1), 105-119. DOI: 10.1002/app.1994.070510112

Stora Enso (2021). "Lumiflex light PE," (https://www.storaenso.com//media/documents/download-center/documents/productspecifications/paper/lumiflex-light-pe_nov20.pdf), accessed 11 January 2021.

Tetsuya, T., Ishiaku, U. S., Mizoguchi, M., and Hamada, H. (2005). "The effect of heat sealing temperature on the properties of OPP/CPP heat seal I. Mechanical 
properties," Journal of Applied Polymer Science 97(3), 753-760. DOI:

10.1002/app. 21320

Theller, H. W. (1989). "Heat sealability of flexible web materials in hot-bar sealing applications," Journal of Plastic Film \& Sheeting 5(1), 66-93. DOI: $10.1177 / 875608798900500107$

Yuan, C., and Hassan, A. (2007). "Effect of bar sealing parameters on OPP/MCPP heat seal strength," eXPRESS Polymer Letters 1(11), 773-779. DOI: 10.3144/expresspolymlett.2007.106

Article submitted: July 17, 2021; Peer review completed: October 4, 2021; Revised version received and accepted: November 1, 2021; Published: November 15, 2021.

DOI: 10.15376/biores.17.1.223-242 